\title{
Agricultural land-use in China: a comparison of area estimates from ground-based census and satellite-borne remote sensing
}

\author{
STEVE FROLKING, XIANGMING XIAO, YAHUI ZHUANG*, WILLIAM SALAS and \\ CHANGSHENG LI Institute for the Study of Earth, Oceans, and Space, Morse Hall, 39 College Road, \\ University of New Hampshire, Durham, NH 03824 USA. E-mail: steve.frolking@unh.edu, \\ xiangming.xiao@unh.edu,bill.salas@unh.edu, changsheng.li@unh.edu, *Research Centerfor Eco-Environmental \\ Sciences, Chinese Academy of Sciences, PO BOX 2871, Beijing 100085, China. E-mail: zhuangyh@sun.ihep.ac.cn
}

\section{ABSTRACT}

We compare estimates of total cropland area, paddy rice area, and irrigated cropland area in China from land cover maps derived from optical remote sensing in 1992-93 (1-km resolution NOAA AVHRR) and county-level agricultural census data for 1990. At national, regional, provincial, and county scales, the total cropland area estimated by remote sensing is $50-100 \%$ higher than reported in the agricultural census. For topographically flat North and Central China, there is a high correlation between countylevel cropland area estimates by the two approaches.
For other regions, the correlation between remote sensing and agricultural census cropland area is much weaker. Throughout China, there is only moderate to weak correlation between remote sensing-based and census-bases estimates of paddy rice area and total irrigated cropland area. It is likely that the census data underestimates and the remote sensing overestimates the actual cropland area. These uncertainties in agricultural land cover estimates will contribute to uncertainty in any largescale biogeochemical analyses.

Key words. AVHRR, China, cropland, land-use, land-cover, paddy rice, remote sensing.

\section{INTRODUCTION}

With an ongoing goal of food self-reliance and $\sim 1.2$ billion people, China's agricultural enterprise is the largest in the world. China currently produces $20 \%$ of the global grain harvest on $9 \%$ of the earth's arable and permanent cropland, accounts for 30\% of global synthetic nitrogen fertilizer use, and contains $20 \%$ of the world's irrigated land (Faostat, 1998). Agriculture on this scale must have a profound influence on planetary biogeochemical cycles (e.g. Matson et al., 1997; Vitousek et al., 1997). Quantitative analysis at this scale will require good estimates of the scale of agricultural land-use.

National, regional, and global-scale land cover maps are being developed based on 1-km resolution National Oceanic and Atmospheric Administration (NOAA) Advanced Very High Resolution Radiometer (AVHRR) imagery (e.g. Loveland \& Belward, 1997).
These land cover maps will be used for global scale analysis of biogeochemical cycling and as baseline data for evaluation of land use and land cover change (e.g. Walker \& Steffen, 1996). Efforts are underway within the IGBP DISCover Program to validate these moderate resolution remote sensing products, in particular regions, with higher resolution imagery from Landsat (Belward, 1996). Additional efforts to evaluate regional landcover products are using local expert knowledge (e.g. Ojima et al., 1997).

We have assembled a county-scale, crop-specific, agricultural database for China in 1990 from Chinese agricultural statistical census data, atlases, and Chinese agronomy books. In this paper we compare this quasispatially explicit, county-scale resolution, cropland landcover database with recent estimates for China derived from NOAA AVHRR (Yang et al., 1997), at county, provincial, regional, and national scales. This provides a simple comparison of these two datasets, 


\section{S. Frolking et al.}

Table I. AC90 Database Cropland Areas

\begin{tabular}{lr}
\hline AC90 Crops & Area $\left(\mathrm{km}^{2}\right)$ \\
\hline Maize & 90500 \\
Cotton & 36300 \\
Potato & 58300 \\
Rape (oilseed) & 34500 \\
Rice (single crop) & 77200 \\
Sorghum & 11600 \\
Soybean & 38700 \\
Sugarbeet & 5200 \\
Sugarcane & 3200 \\
Tobacco & 5700 \\
Vegetables & 135600 \\
Wheat (winter) & 88400 \\
Wheat (spring) & 38600 \\
Small grains (millet, oats, barley, etc.) & 70400 \\
Rice (double crop) & 123900 \\
Rice \& winter wheat (double crop) & 18900 \\
Rice \& rape (oilseed) (double crop) & 16200 \\
Maize \& winter wheat (double crop) & 95000 \\
\hline
\end{tabular}

identifies biases, and identifies those areas that are either consistent or inconsistent between the datasets.

\section{AGRICULTURAL CENSUS DATABASE}

County-level agricultural census data for China in 1990 were prepared from three sources: 1) the EcoEnvironmental Database (unpublished) of the Research Center for Eco-Environmental Sciences, Chinese Academy of Sciences; 2) Chinese agronomy books (CRTSA, 1995; Huang et al., 1997); and 3) consultation with the Chinese Academy of Agricultural Sciences (Professor Qingmu Chen, personal communication). The database contains county statistics on crop acreage (Table 1) and yields for major crops, acreage of total cropland, sown area, grassland, and irrigated upland cropland, nitrogen fertilizer use, and livestock and human populations. These data are available for 2483 counties in China (excluding Taiwan, Hongkong, Macao, and the numerous small islands in the South China Sea-Xisha Qundao, Nansha Qundao, Zhongsha Qundao). The database has been used previously for an analysis of crop residue production in China (Zhuang et al., 1996). Hereafter, this dataset will be called AC90.

Harvesting two crops from a single plot in a single year (double cropping) is common in much of China. The cropland area data reflects the actual land area in crops, while the sown area data double counts land that is double cropped. Some counties report sown area as nearly double-crop area (i.e. virtually all cropland is double cropped) and the AC90 total sown area for China is $27 \%$ greater than the AC90 total cropland area. Major double-cropping practices in China are rice/rice, maize/winter wheat, rice/winter wheat, and rice/rape (oilseed) (CRTSA, 1995; Huang et al., 1997). We estimated areas double cropped in each of these four categories based on the difference between total cropland and sown areas, and the area of rice, maize, winter wheat and rape for each county. For this estimation, we prioritized crops in this order: rice, maize, winter wheat, and rape. The calculated areas meet the total cropland area, sown area, and each individual crop area (single plus double cropped), but the crop distribution into single and double-crop totals may be not exactly consistent with the real situation. There is still some triple cropping in southern Guangdong and Hainan Provinces, which we treated as double cropping because we consider this area to be fairly small (at a national scale) and expect that it would be difficult to classify from AVHRR remote sensing due to that region's cloudiness. The AC90 irrigation index is the irrigated fraction (excluding rice) of the total upland crop acreage in each county.

\section{CHINA LAND COVER CHARACTERISTICS DATABASE}

The China Land Cover Characteristics Database was produced at the US Geological Survey EROS Data Center in co-operation with the Chinese Academy of Surveying and Mapping (Yang et al., 1997). The classification of seasonal land cover regions (SLCR) was based on 1-km resolution NOAA AVHRR-derived monthly NDVI composite data from April 1992 to March 1993. Ancillary data used in the classification included atlases, regional and provincial maps published in China, Landsat data, and global ecosystem databases (Zhiliang Zhu, USGS, personal communication 1998). The 153 distinct spectral classes were mapped into 118 landcover classes. Of these, 25 classifications contain at least some agricultural cropland. We excluded plantation/horticulture classifications (e.g. tea, rubber, eucalyptus, and bamboo) from our analysis as we had no AC90 data for these crops. Fourteen of the cropland land covers were classified as a mixture of cropland and noncropland (e.g. 'grassland and cropland mosaic'). 
Comparison of cropland estimates for China 409

The remaining 11 were classified as 'pure' cropland. Of these, one class was 'paddy rice', one was 'irrigated cropland', two were 'irrigated and dry cropland', and seven were classified as nonirrigated crops. Only one SLCR classification specifically mentions double cropping ('double cropping irrigated and dry').

\section{SPATIAL AND LANDCOVER AGGREGATIONS FOR ANALYSIS}

To compare SLCR landcover with the agricultural statistics database, we aggregated both datasets into three separate classifications:

1 'Total cropland'-The basic measure of agricultural land use. We calculated this for SLCR as both the sum of all pure cropland pixels (SLCR-pure) and as this pure cropland total plus half the area of the mixed cropland/noncropland pixels (SLCR-mixed). SLCR-mixed will be a very rough estimate, due to the simple assumption of $50 \%$ of mixed-pixel area.

2 'Paddy rice'-Rice production is a major agricultural effort in China whose intermittent flooding could generate a distinct remote sensing signature (Malingreau, 1986; Bachelet, 1995). For AC90, 'paddy rice' includes all rice (paddy and upland). In China, approximately $93 \%$ of rice cropland is irrigated, $5 \%$ is rain-fed lowland rice, and $2 \%$ is upland (dry) rice (Hossain, 1997). We report two areas: land with single or double-cropped rice (AC90-rice), and this area plus land area with rice/wheat or rice/rape double cropping (AC90total-rice).

3 'Total irrigated cropland'-Increasing irrigation has contributed increases in grain production in China over the last several decades (Xu, 1996), but rapid development of an industrial economy and urban expansion has generated a competition for water that has recently led to declines in irrigated area (Xu, 1996; Zuo \& Xu, 1996). Non-agricultural water demands are likely to increase in the future. To calculate SLCR 'total irrigated cropland' we aggregated irrigated cropland, paddy rice, and onehalf the area of the two mixed irrigated/nonirrigated cropland classes; AC90 'total irrigated cropland' equals total rice area plus all other irrigated area. The 1:1000 000 scale, county-level template for our geographical analysis (CIESIN, 1998) represents China's national, provincial, regional and county administrative boundaries as of 31 December 1990. We re-projected the county boundary coverage (Lambert conformal conic projection) to Lambert azimuth projection (the SLCR projection), and then gridded the polygon county coverage at 1-km resolution (using ARC/INFO v.7.1.1). We overlaid the gridded county boundary map on the SLCR land cover map and counted pixels in each land cover class within each county boundary. These county-aggregate SLCR values were compared with AC90 estimates of crop and irrigated area at the county level, and both datasets were aggregated to provincial, regional, and national levels (Table 2). In 1990, China had 2833 county-level units: 1723 counties, 121 autonomous counties, 51 banners, three autonomous banners, 279 county-level cities, and 651 municipal, one industrial-agricultural, one forest, and three special districts (Institute of Geography, 1994). The agricultural census data reported crop areas for 2483 counties. The CIESIN political boundary map had 2760 polygons representing 2383 mainland counties. These two county lists were not completely consistent, so we merged those counties in either collection that corresponded to a single county in the other collection (based on county names and reported location). This resulted in a common list of 2369 county-level administrative units. There were 19 county-level units in the CIESIN map and one from AC90 that could not be mapped into a corresponding county from the other list; these were excluded from all subsequent analyses.

\section{RESULTS}

\section{National and regional scales}

Cropland

The SLCR-pure estimate of China's cropland area is around $50 \%$ higher than the agricultural census, and the SLCR-mixed estimate is about $100 \%$ higher (Table 2). At the regional level this pattern of lower estimates by AC90, higher estimates for SLCR-pure pixels, and highest estimates for SLCR-mixed is repeated, except for South China where the SLCRpure area estimate was the lowest (Fig. 1a, Table 2). For North, North-east, and Central China, the SLCRmixed cropland is about 5-55\% higher than SLCRpure cropland area, while for the other three regions the SLCR-mixed estimate is $75-550 \%$ higher (Table 2). These regional differences are primarily topographical, as agriculture in North, North-east and Central China mostly occupies broad, relatively flat plains, while the 


\section{S. Frolking et al.}

Table 2. Cropland areas $\left(\mathrm{km}^{2}\right)$ in China by province and region from the Agricultural Census of 1990 (AC90) and derived from 1992-1993 AVHRR signals (SLCR)

\begin{tabular}{|c|c|c|c|c|c|c|c|c|c|}
\hline \multirow[b]{2}{*}{ Region } & \multirow[b]{2}{*}{ Land area* } & \multicolumn{3}{|c|}{ Cropland } & \multicolumn{3}{|l|}{ Rice } & \multicolumn{2}{|l|}{ Irrigated } \\
\hline & & AC90 & $\begin{array}{c}\text { SLCR } \\
\text { pure } \dagger\end{array}$ & $\begin{array}{l}\text { SLCR } \\
\text { mixed }\end{array}$ & $\begin{array}{l}\text { AC90 } \\
\text { pure rice** }\end{array}$ & $\begin{array}{l}\text { AC90 } \\
\text { total ricet }\end{array}$ & $\begin{array}{l}\text { SLCR } \\
\dagger\end{array}$ & AC90末t & SLCR \\
\hline Total China & 9102749 & 950810 & 1402968 & 1941652 & 200976 & 236091 & 315936 & 433657 & 780371 \\
\hline North China & 669102 & 250761 & 420639 & 473687 & 3976 & 6774 & 31609 & 139145 & 313178 \\
\hline Beijing & 16261 & 4447 & 5425 & 6854 & 243 & 352 & 477 & 3147 & 4463 \\
\hline Tianjin & 11212 & 3983 & 8581 & 9073 & 295 & 382 & 17 & 1399 & 5153 \\
\hline Hebei & 181554 & 65434 & 103719 & 120058 & 707 & 1373 & 5069 & 39509 & 75,346 \\
\hline Shanxi & 151390 & 37516 & 54140 & 74690 & 32 & 85 & 4742 & 11594 & 35299 \\
\hline Shandong & 147530 & 68842 & 122026 & 132708 & 86 & 529 & 4332 & 47188 & 103719 \\
\hline Henan & 161154 & 70540 & 126748 & 130305 & 2612 & 4052 & 16972 & 36307 & 89067 \\
\hline North-east China & 787577 & 141832 & 310306 & 325821 & 13254 & 14813 & 3682 & 21394 & 12008 \\
\hline Liaoning & 151257 & 36741 & 81707 & 88466 & 4586 & 4942 & 1913 & 7542 & 8266 \\
\hline Jilin & 187337 & 37907 & 81254 & 84165 & 3509 & 4019 & 607 & 8481 & 1228 \\
\hline Heilongjiang & 452311 & 68785 & 150033 & 155879 & 5322 & 6027 & 1162 & 5873 & 2515 \\
\hline Central China & 880752 & 198497 & 284789 & 353165 & 95748 & 113382 & 1944341 & 116483 & 267504 \\
\hline Shanghai & 6744 & 3357 & 5217 & 5450 & 1569 & 2021 & 1758 & 2117 & 4796 \\
\hline Jiangsu & 98276 & 45442 & 80156 & 83391 & 15439 & 23022 & 43895 & 23202 & 76105 \\
\hline Zhejiang & 100954 & 18921 & 13215 & 21565 & 13367 & 15019 & 9852 & 14783 & 12710 \\
\hline Anhui & 133363 & 42487 & 744329 & 82203 & 11905 & 15820 & 43407 & 16010 & 70700 \\
\hline Jiangxi & 164214 & 23067 & 24469 & 50344 & 16667 & 17388 & 21893 & 18063 & 21893 \\
\hline Hubei & 167870 & 32080 & 59910 & 69804 & 12124 & 14773 & 48790 & 16714 & 48790 \\
\hline Hunan & 209599 & 33222 & 27576 & 40497 & 24679 & 25338 & 24825 & 25899 & 24825 \\
\hline South China & 573398 & 93981 & 26197 & 142676 & 56643 & 57284 & 7710 & 57659 & 9272 \\
\hline Fujian & 119588 & 12266 & 3841 & 31656 & 8945 & 9072 & 766 & 9090 & 1204 \\
\hline Guangdong & 182742 & 25767 & 11743 & 59167 & 16117 & 16225 & 2224 & 15721 & 2675 \\
\hline Guangxi & 233252 & 51238 & 9373 & 47227 & 29109 & 29494 & 4422 & 30477 & 4758 \\
\hline Hainan & 36891 & 4465 & 1156 & 4209 & 2262 & 2284 & 288 & 2318 & 624 \\
\hline South-west China & 1108562 & 109401 & 143770 & 260064 & 29939 & 40664 & 57061 & 41694 & 80678 \\
\hline Sichuan & 550617 & 62442 & 105071 & 168317 & 19167 & 26237 & 45542 & 26381 & 53225 \\
\hline Guizhou & 174028 & 18514 & 144331 & 42432 & 2948 & 6047 & 9230 & 6254 & 12280 \\
\hline Yunnan & 383917 & 28445 & 244368 & 49315 & 7825 & 8380 & 2289 & 9059 & 15144 \\
\hline North-west China & 5083358 & 156338 & 217267 & 386240 & 1415 & 3176 & 21533 & 57281 & 97733 \\
\hline Inner Mongolia & 1134179 & 49658 & 944305 & 164033 & 185 & 672 & 788 & 13249 & 26956 \\
\hline Tibet & 1132299 & 2633 & 10264 & 35792 & 0 & 0 & 2357 & 607 & 4322 \\
\hline Shaanxi & 198779 & 35215 & 39582 & 64583 & 767 & 1566 & 10652 & 11296 & 30633 \\
\hline Gansu & 390503 & 33693 & 32440 & 55258 & 5 & 42 & 7044 & 9907 & 15633 \\
\hline Qinghai & 584455 & 5189 & 4631 & 10712 & 0 & 0 & 552 & 1336 & 1811 \\
\hline Ningxia & 48405 & 7746 & 3961 & 7099 & 236 & 240 & 11 & 1209 & 1312 \\
\hline Xinjiang & 1593426 & 21991 & 31827 & 48437 & 157 & 589 & 128 & 19677 & 16889 \\
\hline
\end{tabular}

*CIESIN polygon coverage (HTTP://sedac.ciesin.org/china/admin/bnd90/bnd90.html) including only the 2369 counties used in our analysis (see text for details); †SLCR pure: includes only pixels classified as pure cropland (excludes woody crops). SLCR data developed by Yang et al., 1997; †SLCR mixed: includes pure pixels plus half the area of the pixels classified as mixed cropland and noncropland (excludes woody crops); ${ }^{* * A C} 90$ pure rice: land area with single or double-cropped rice only; ††AC90 total rice: land area with single or double-cropped rice plus land area with rice/wheat, rice/maize, or rice/rape double cropping; $\$$ 刦 90 irrigated: includes all rice and other irrigated crops; §SLCR irrigated: includes all paddy rice and irrigated cropland pixels, plus half the area of the mixed irrigated and dry cropland pixels. 

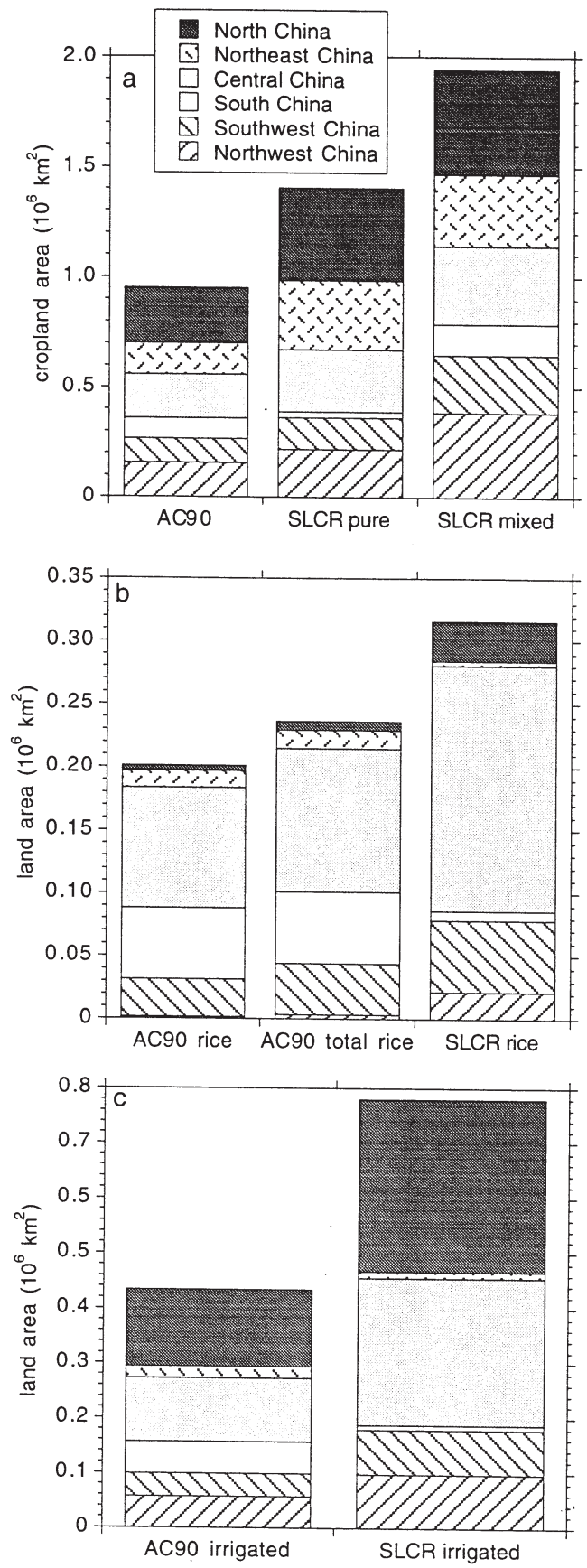

Fig. I. Regional land area totals, based on 1990 agricultural census data (AC90) and 1992-93 remote sensing land cover classification (SLCR) for (a) cropland (b) paddy rice, and (c) irrigated cropland in China. SLCR-pure includes only pixels classified as pure cropland; SLCR-mixed includes pure pixel area plus half the area of the mixed crop/noncrop pixels. AC90-rice is single and double-cropped rice; AC90-total-rice adds to this the area of rice/wheat and rice/rape (oilseed) double cropping. Irrigated land includes paddy rice in all regions. See Table 2 for a list of the provinces in each region. 


\section{S. Frolking et al.}

landscape of southern and south-western China is much hillier, leading to generally smaller field sizes and a more heterogeneous landscape. Both AC90 and SLCR have similar distributions of cropland area across China (Fig. 1a), and their differences at this scale are primarily in magnitude. Provincial patterns for total cropland are similar to the regional patterns (Table 2).

\section{Rice}

The SLCR-pure estimate of China's paddy rice area is also about 50\% higher than that for AC90-rice (Table 2, Fig. 1b). At the regional scale, however, the discrepancies are generally larger, with SLCR estimates of rice area many times larger than those for AC 90 for North and North-west China, and many times lower for North-east and South China (Table 2, Fig. 1b). Both datasets locate the largest rice area in Central China.

\section{Irrigated land}

The SLCR-pure estimated area of irrigated cropland is about $75 \%$ higher than the AC90 estimate (Table 2, Fig. 1c). SLCR estimates were roughly double AC90 values for North, Central, South-west, and North-west China, half the AC90 value in North-east China, and about $15 \%$ of the AC90 value in South China. These relationships are very similar to those for paddy rice.

\section{County scale}

To develop a meaningful comparison between ground census and remote sensing estimates, we limited the county-scale comparison between SLCR and AC90 to those counties with significant agricultural land use and relatively homogeneous land cover. We included only those counties in which: 1) at least $25 \%$ of the total county land area was cropland according to AC 90 (Fig. 2a) and; 2) SLCR-pure cropland area accounted for at least $75 \%$ of the SLCR-mixed cropland area (Fig. 2b). The 683 counties satisfying these criteria account for $10 \%$ of China's land area and $45 \%$ of China's cropland (based on AC90 data); $80 \%$ of these counties are in North or Central China. This subsetting excluded most of the counties in South China, where the combination of a hilly landscape and persistent cloud cover will have made the classifying of landcover by optical remote sensing more problematic (Qiu et al., 1996), and most cropland pixels were mixed.
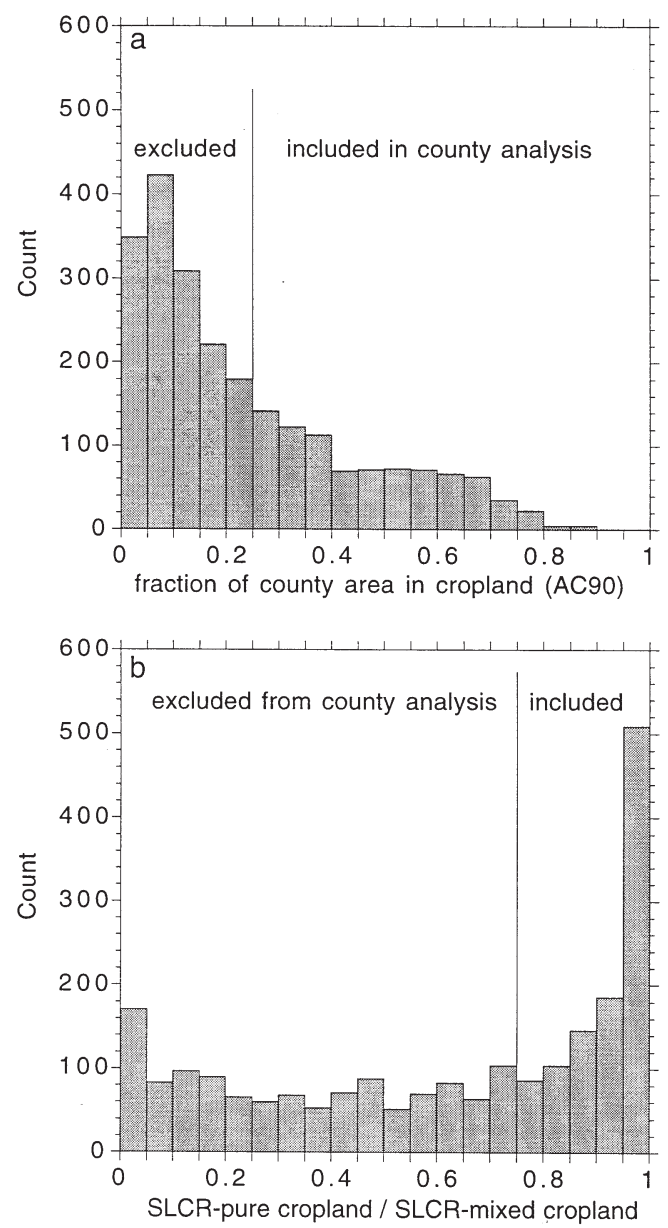

Fig. 2. (a) Frequency distribution of fraction of 1990 county land area in cropland (AC90 data); (b) Frequency distribution of ratio of SLCR-pure (SLCR estimate of cropland area in pure pixels) to SLCR-mixed (SLCR estimate of cropland in pure pixels plus half the area in mixed cropland/noncropland pixels for 1992-93). For the county level analysis we considered only those counties with greater than $25 \%$ of the land area in crops, and with an SLCR-pure:SLCR-mixed ratio greater than 0.75 , i.e. those counties that fell in the 'included' portions of both panel (a) and panel (b). The 683 counties satisfying these criteria account for $10 \%$ of China's land area and $45 \%$ of China's cropland (based on AC90 data); $80 \%$ of these counties are in North or Central China.

\section{Cropland}

There was a strong correlation $\left(r^{2}=0.82\right)$ at the county scale between the AC90 and SLCR-pure estimates of cropland area, with SLCR-pure estimates averaging 
Comparison of cropland estimates for China 413

about 70\% higher than AC90 (Fig. 3a). The SLCRmixed dataset gives a very similar result (not shown) because the cropland in this subset of counties is dominated by pure pixels.

\section{Rice}

There was a moderate correlation $\left(r^{2}=0.45\right)$ at the county scale between AC90-total-rice and SLCR-pure estimates of paddy rice area (Fig. 3b). The AC90-rice and SLCR-pure paddy rice areas had poorer correlation $\left(r^{2}=0.32\right.$; not shown). The 683 county database subset had 119 counties with SLCR paddy rice area greater than $10 \mathrm{~km}^{2}$ for which $\mathrm{AC} 90$ reported no rice, and 57 counties with AC90-rice area greater than $10 \mathrm{~km}^{2}$ for which SLCR detected no paddy rice.

\section{Irrigated land}

There was a weak correlation $\left(r^{2}=0.23\right)$ at the county scale between AC90 and SLCR estimates of irrigated area (Fig. 3c). The 683 county database subset had 43 counties with SLCR irrigated area greater than $10 \mathrm{~km}^{2}$ for which AC90 reported none, and 30 counties with AC90 irrigated area greater than $10 \mathrm{~km}^{2}$ for which SLCR detected no irrigation.

\section{DISCUSSION AND CONCLUSIONS}

The AC90 cropland area estimate $\left(950810 \mathrm{~km}^{2}\right)$ is within $1 \%$ of the national total provided by China's State Statistical Bureau (SSB) in their annual report (e.g. SSB, 1994). Remote sensing-based estimates of $1992 / 1993$ cropland area in China are $48 \%$ higher (SLCR-pure) and 104\% higher (SLCR-mixed) than the agriculture census estimate of 1990 cropland area (AC90). Other cropland area estimates are also higher than the AC90 and SSB totals. Fischer et al., (1998) summarize ground census data reported by China's State Land Administration, estimating the 1990 total arable land area at $1225100 \mathrm{~km}^{2}, 29 \%$ greater than the AC90 estimate. The Food and Agricultural Organization of the United Nations reports a comparable total arable land area for China in 1990, $1236780 \mathrm{~km}^{2}$ (Faostat, 1998). Researchers at the Institute of Geography, Chinese Academy of Sciences have developed a 1:1000 000 land use map of China, based on satellite images (1:500 000-1:1000 000) and large-scale aerial photographs from the 1980s (Wu 1990; Wu \& Guo, 1994). They estimate the cultivated land area of China at $1364000 \mathrm{~km}^{2}$ (including cropland area in Taiwan, Hongkong, and Macao, which contain $<1 \%$ of China's total cropland area in the SLCRmixed estimate), $43 \%$ greater than the AC90 estimate.

Three factors probably contribute to these cropland area discrepancies. First, the SSB states, 'Figures for the cultivated areas are underestimated and must be further verified' (SSB, 1994; p. 329); this underreporting is probably also true for AC90 (Zhuang et al., 1996). Recent estimates are that actual cropland is $15-50 \%$ greater than reported by the SSB, with regional and crop type variations (Crook, 1993; Fu et al., 1993). Second, these estimates may not be counting exactly the same things. For example, the AC90 and SSB databases refer to planted cropland, while the FAO definition of arable land includes 'temporary meadows for mowing or pasture' and 'land temporarily fallow (less than 5 years)' (Faostat, 1998). This broader cropland definition may also apply to estimates by Fischer et al., (1998) and Wu \& Guo, (1994). A third factor is the inherent overestimate in our remotesensing analysis. If a pixel is classified as pure cropland, we allocate the entire area of that pixel to crops, with no land area for infrastructure (e.g. roads, dwellings, other buildings, idle land). The amount of noncropland area in each pure cropland pixel may vary from 10 to 40\% (e.g. Okamoto \& Fukuhara, 1996; Fang, 1998; Gonzalez-Alonso et al., 1998). In the Jianghan Plain, a flat region with widespread rice cultivation in southern Hubei Province, $\sim 10-20 \%$ of the landscape is agricultural infrastructure which would be identified as crop lands by moderate to coarse resolution remotesensing analysis (Fang et al., 1998). This problem probably also occurred to a lesser degree for the cropland polygons in the 1:1 000000 Land-Use Map of China of $\mathrm{Wu}$ (1990). Applying a 20\% infrastructure area to the pure pixels reduces the SLCR-pure cropland area $1122000 \mathrm{~km}^{2}, 18 \%$ greater than the AC90 estimate. If mixed cropland/noncropland pixels (total area to $1077000 \mathrm{~km}^{2}$ ) are only $10-20 \%$ cropland, then the SLCR-mixed cropland area is similar to estimates of the FAO (Faostat, 1998), Fischer et al., (1998), and Wu \& Guo, (1994). Two independent groups estimate cropland area loss from 1990 to 1993 at about 1\% (SSB, 1994; Fischer et al., 1998), so land use change is not the source of the discrepancy.

Discrepancies between AC90 and SLCR-pure estimates of total cropland area at the regional and provincial scales are generally greater than for the national total, because the large underestimate by SLCR-pure for South China compensates likely 


\section{$4 \mid 4$ S. Frolking et al.}
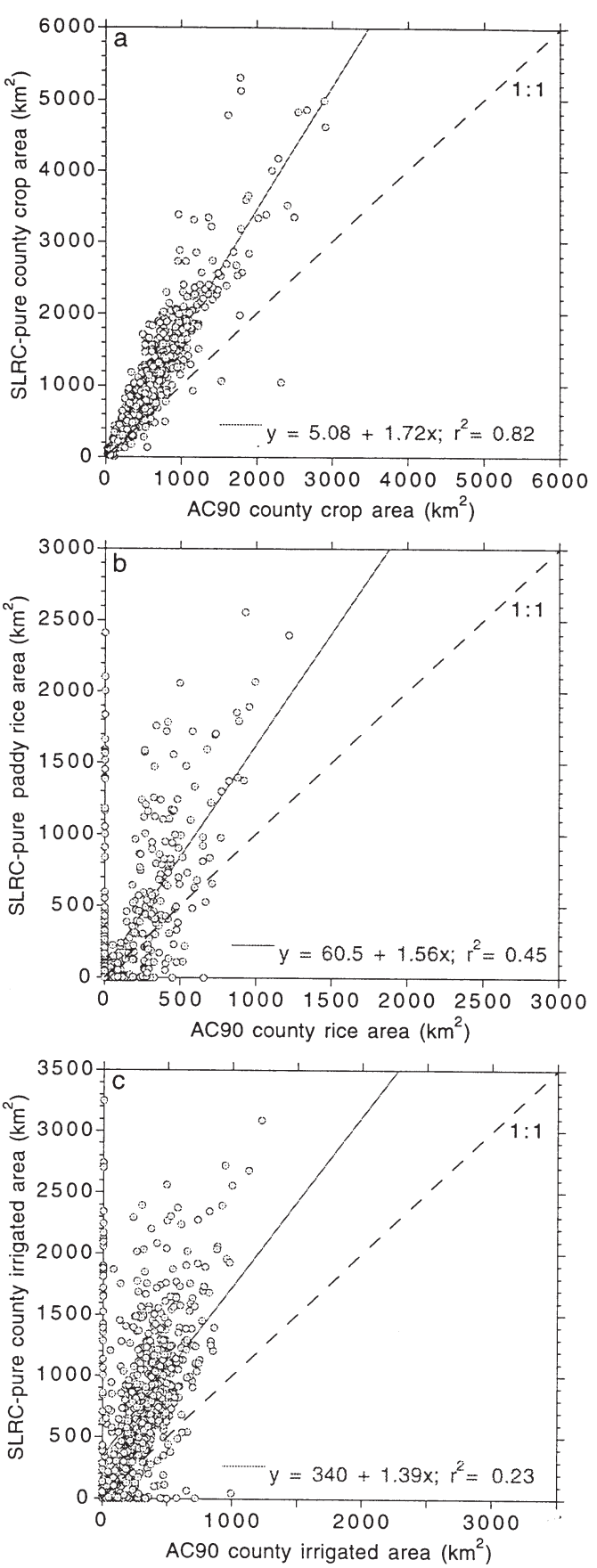

Fig. 3. AC90 vs. SLCR-pure estimates of county land area totals for (a) cropland (b) paddy rice, and (c) irrigated cropland in 683 counties in China. These counties were selected for having more than $25 \%$ of their total land area in cropland in the AC90 database (1990 land-use) and at least 50\% more pure than mixed cropland pixels in the SLCR database (1992-93 land-use) (see Fig. 2). The AC90 rice area is 'total rice', including that land in rice/wheat or rice/rape (oilseed) double cropping. All SLCR totals are based on pixels classified as pure cropland. Irrigated land includes paddy rice in all counties. 
Comparison of cropland estimates for China 415

overestimates in other regions (Table 2). However, provincial area estimates are generally consistent with the finer-scale county estimates for the dense agricultural regions, where it appears that there is good correlation between the two estimates. The real area likely lies between the AC90 and SLCR totals. In many regions of China, however, the correlation between county-level cropland estimates of AC90 and SLCR was weak (e.g. $r^{2} \sim 0.14$ for all counties in South, Southwest, and North-west China). These regions probably have higher levels of under-reporting to AC90 (Crook, 1993; Fischer et al., 1998), and are a challenge to optical remote-sensing analysis because of frequent cloud cover in the south (Qiu et al., 1996) and a high percentage of mixed pixels with unknown fractional cropland areas. Cropland estimates in these regions may not be well-constrained by these databases.

Correlations between AC90 and SLCR estimates of paddy rice area or total irrigated agriculture were weaker (Table 2, Figs 3a, 3b). Even in the highly agricultural regions of North and Central China, more than $25 \%$ of the counties were identified as having significant paddy rice area by one analysis and none by the other (Fig. 3b). Identification of paddy rice with AVHRR NDVI data requires a cloud-free image during the period of initial flooding (NDVI very low) and subsequent cloud-free images during peak growing season (high NDVI). This is difficult to achieve with significant cloud contamination of the NDVI signals (Qiu et al., 1996). Estimating irrigated area will also be difficult, as the seasonal remote sensing signal, based on 1 year of AVHRR data, may not be strong. AC90 irrigated area data are probably based on reports of areas where some irrigation infrastructure existed (i.e. potential irrigation if everything was working), but may not be a good estimate of actual irrigation.

County scale evaluation of national and regional remote sensing products can provide an important ground-level test at a resolution intermediate between field observation at the pixel scale and regional and national scale statistics commonly reported in almanacs and on-line databases. Analysis at this scale can help identify regions where land cover classifications are more and less successful, and also point out probable discrepancies in census and almanac data sets. We believe that SLCR and AC90 put a realistic constraint on cropland area in North and Central China. For the rest of China, and for paddy rice and irrigated areas, there are large and as yet unresolved discrepancies between AC90 and SLCR estimates. The new generation of optical sensors due for launch in 1999/
2000 (MODIS, MISR, ASTER on EOS-AM1, and ETM on Landsat 7) have been designed for studying vegetation and landcover, and should substantially improve remote-sensing mapping and monitoring of vegetation and land cover types (Kaufman et al., 1998). Improved ground-based datasets also need to be developed.

\section{ACKNOWLEDGMENTS}

This work was supported by a grant from the Terrestrial Ecology Program, jointly supported by NASA, NSF, EPA, DOE, and the USDA, by the Chinese Natural Science Foundation under contract number 39790100 , and also by a grant from the NASA EOS Interdisciplinary Science Program. We thank Zhi-liang Zhu and two anonymous reviewers for helpful comments on an earlier draft.

\section{REFERENCES}

Bachelet, D. (1995) Rice paddy inventory in a few provinces of China, using AVHRR data. Geocarto Int. 10, 23-38. Belward, A.S. (1996) The IGBP-DIS global $1 \mathrm{~km}$ land cover data set (DISCover): Proposal and implementation plans. IGBP-DIS Working Paper. IGBP-DIS Office, Meteo-France, 42 Av. G. Coriolis, F-31057 Toulouse, France.

CIESIN (Consortium for International Earth Science Information Network) (1998) The China Time Series Administrative Regions GIS Data: 1:1M, County Level, prepared by CIESIN, the Chinese Academy of Surveying and Mapping, and China in Time and Space (University of Washington), available on the World Wide Web at http://sedac.ciesin.org/china/admin/bnd90/bnd90.html.

CRTSA (Central Radio and Television School of Agriculture) (1995). Textbooks for Primary Agricultural Technology Training, Volumes. I-VI. China Agricultural Publishing House, Beijing (in Chinese).

Crook, F. (1993) Underreporting of China's cultivated land area: Implications for world agricultural trade. China International Agricultural and Trade Report, pp. 33-39. 1993 Situation and Outlook Series RS-93-4. US Department of Agriculture, Washington, DC.

Fang, H., Wu, B., Liu, H. \& Huang, X. (1998) Using NOAA AVHRR and Landsat TM to estimate rice area year-by-year. Int. J. Remote Sens. 19, 512-525.

Fang, H. (1998) Rice crop area estimation of an administrative division in China using remote sensing. Int. J. Remote Sens. 19, 3411-3419.

Faostat (1998) Statistical Database of the Food and Agricultural Organization of the United Nations, available on the World Wide Web at http://apps.fao.org. 


\section{S. Frolking et al.}

Fischer, G., Chen, Y.F. \& Sun, L.X. (1998) The balance of cultivated land in China during 1988-95. Internat. Inst. Appl. Syst. Analysis (IIASA) Interim Report IR98-047, Laxenburg, Austria.

Fu, L.Q., Zhang, S.W., Liu, D.W. \& Wan, E.P. (1993) Image processing for maize yield estimation by remote sensing. Remote Sensing Technique for Wheat, Maize, and Rice Yield Estimation (ed. by B.S. Chen), pp. 8-15. China Science and Technology Press, Beijing (in Chinese).

Gonzalez-Alonso, F., Cuevas, J.M., Arbiol, R. \& Baulies, X. (1998) Remote sensing and agricultural statistics: crop area estimation in north-eastern Spain through diachronic Landsat TM and ground sample data. Int. J. Remote Sens. 18, 467-470.

Hossain, M. (1997) Rice supply and demand in Asia: A socioeconomic and biophysical analysis. Applications of Systems Approaches at the Farm and Regional Levels (ed. by P.S. Teng, P.S.M.J. Kropff, H.F.M. ten Berge, et al.). Kluwer Academic Publishers, Dordrecht, Germany. Huang, G., Zhang, Z. \& Zhao, Q. (1997). Crop Practice in Southern China. China Agricultural Publishing House, Beijing (in Chinese).

Institute of Geography \& Chinese Academy of Science, State Planning Committee, State Economic Information Center, and Institute of Statistics, State Statistical Bureau. (1994) National Economic Atlas of China, p. 314. Oxford University Press, Oxford UK.

Kaufman, Y.J., Herring, D.D., Ranson, K.J. \& Collatz, G.J. (1998) Earth Observing System AM-1 mission to Earth. IEEE Trans. Geosci. Remote Sens. 4, 1045-1055.

Loveland, T.R. \& Belward, A.S. (1997) The IGBP-DIS global $1 \mathrm{~km}$ land cover data set, DISCover: first results. Int. J. Remote Sensing. 18, 3289-3295.

Malingreau, J.-P. (1986) Global vegetation dynamics: satellite observations over Asia. Int. J. Remote Sens. 7, 1121-1146.

Matson, P.A., Parton, W.J., Power, A.G. \& Swift, M.J. (1997) Agricultural intensification and ecosystem properties. Science, 277, 504-509.

Ojima, D.S., Stretch, L., Chuluun, T., et al. (1997) Development of the temperate east Asia land-cover (TEAL) database. Proceedings of the IGU-LUCC'97
Meeting on Information Bases for Land Use/Cover Change Research (ed. by Y. Himiyama \& L. Crissman), pp. 77-83. International Geogr. Union, Asahikawa, Japan.

Okamoto, K. \& Fukuhara, M. (1996) Estimation of paddy field area using the area ratio of categories in each pixel of Landsat TM. Int. J. Remote Sens. 17, 1735-1749.

Qiu, Z., Yang, L. \& Loveland, T.R. (1996) Recent experiences in mapping land cover from AVHRR data: People's Republic of China test sites. Proc. IGARSS 96, 2318-2320.

SSB (State Statistical Bureau) (1994). Statistical Yearbook of China 1994, p. 795. China Statistical Publishers House, Beijing.

Vitousek, P.M., Mooney, H.A., Lubchenco, J. \& Melillo, J.M. (1997) Human domination of earth's ecosystems. Science, 277, 494 499

Walker, B. \& Steffen, W., eds. (1996) Global Change and Terrestrial Ecosystems, p. 619. Cambridge University of Press, Cambridge, UK.

Wu, C. (ed.) (1990) Land-Use Map of China (1:1 000000 scale). Science Press, Beijing (in Chinese).

Wu, C. \& Guo, H. (1994). Land-Use in China, p. 442. Science Press, Beijing (in Chinese).

$\mathrm{Xu}$, Y. (1996) Irrigated farming of the North China Plain. Experimental Studies on Water and Energy Balance in Agricultural Lands (ed. by D. Tang, \& X. Xie), pp. 151-160. China Meteorological Press, Beijing.

Yang, L., Zhu, Z., Li, J. \& Qiu, Z. (1997) Seasonal land cover characteristics database of China for global change research. Proceedings: 1997 ASPRS/ACSM Annual Convention \& Exposition, ASPRS technical papers, 2, pp. 82-86. Bethesda, MD, USA.

Zhuang, Y.H., Cao, M., Wang, X. \& Yao, H. (1996) Spatial distribution of trace-gas emissions from burning crop residue in China. Biomass Burning and Global Change, Vol. 2 (ed. by J.S. Levine), pp. 764-770. MIT Press, Cambridge, MA

Zuo, D. \& Xu, Y. (1996) The shortage of water resources in the Northern Territory of China and its mitigation countermeasures. Experimental Studies on Water and Energy Balance in Agricultural Lands (ed. by D. Tang \& X. Xie), pp. 1-12. China Meteorological Press, Beijing. 